\title{
The clinical application of linagliptin in Asians
}

This article was published in the following Dove Press journal:

Therapeutics and Clinical Risk Management

16 September 2015

Number of times this article has been viewed

\author{
Chu-qing Cao \\ Yu-fei Xiang \\ Zhi-guang Zhou
}

Key Laboratory of Diabetes Immunology, Ministry of Education, National Clinical Research Center for Metabolic Diseases, Institute of Metabolism and Endocrinology, The Second Xiangya Hospital, Central South University, Changsha, Hunan, People's Republic of China
Correspondence: Zhi-guang Zhou Key Laboratory of Diabetes Immunology, Ministry of Education, National Clinical Research Center for Metabolic Diseases, Institute of Metabolism and Endocrinology, The Second Xiangya Hospital, Central South University, Changsha, Hunan 4I00II, People's Republic of China

Tel +86 73I 85292 2I54

Fax +8673 I 85267220

Email zhouzg@hotmail.com
Abstract: Asia has a growing diabetic population. Linagliptin, a member of dipeptidyl peptidase-4 inhibitor class, is unique in its nonlinear pharmacokinetics with the characteristics of rapid attainment of steady state, little accumulation, predominantly nonrenal route of elimination, prolonged terminal half-life, and sustained inhibition of dipeptidyl peptidase-4 enzyme. No clinically relevant difference in pharmacokinetics was observed between Asians and non-Asians. The management of type 2 diabetes is increasingly challenging with the progression of disease, especially with the requirements of minimal hypoglycemia, weight gain, fluid retention, and other adverse effects. Linagliptin was efficacious and well-tolerated in Asian type 2 diabetes patients with or without renal or hepatic dysfunctions, comparable to that in Caucasians. This review will focus on the usage of linagliptin in clinical studies in Asians.

Keywords: linagliptin, Asians, type 2 diabetes

\section{Introduction}

In 2014, the International Diabetes Federation (IDF) announced that the prevalence of diabetes was $8.3 \%$, with 387 million people living with diabetes. ${ }^{1}$ The IDF also predicted that there would be 205 million more people affected worldwide in 2035 , which is a rapid growth with greater magnitude than previously expected. ${ }^{2}$ It is estimated that $>60 \%$ of the whole population with diabetes will have an Asian derivation, as it remains the world's most densely populated region. ${ }^{3}$ Such a tremendous number puts a huge financial burden, owing to direct health care expenditure and impairment of productivity, on developing regions.

Asians with the same age, sex, and BMI, particularly those of South Asian lineage, have a higher body fat percentage and are more prone to central obesity and insulin resistance (IR) than their western counterparts. Furthermore, insufficiency of the compensatory insulin secretion capacity, which could not increase proportionately with the severity of IR, is another characteristic of Asian type 2 diabetic population. ${ }^{3}$

Another characteristic of Asian diabetic patients is the higher risk of renal complications when compared with their Caucasian counterparts. ${ }^{4}$ Many oral antihyperglycemic agents need dose adjustments or to be avoided in patients with diabetic nephropathy, even under periodic renal function examinations. ${ }^{5}$ Most patients with diabetic nephropathy have to finally turn to exogenous insulin therapy, despite its adverse effects including increased rates of hypoglycemia due to impaired renal function, exacerbated fluid retention, and weight gain. ${ }^{6} \mathrm{New}$ and more effective treatments are under development.

Dipeptidyl peptidase-4 (DPP-4) inhibitors suppress the enzymatic degradation of incretin hormones, including glucagon-like peptide-1 (GLP-1) and glucose-dependent insulinotropic polypeptide (GIP), which could promote the biosynthesis of insulin and further stimulate insulin release glucose-dependently in addition to oral glucose load, and this phenomenon was absent with intravenous glucose infusion. ${ }^{7}$ When 
administrated at pharmacological doses, GLP-1 also has other non-insulinotropic effects, including inhibition of postprandial glucagon excursions, suppression of gastric emptying and intestinal mobility, induction of satiety, and weight loss. ${ }^{8}$ Moreover, GLP-1 exhibits a protecting/preserving effect of $\beta$-cells in animal experiments. Thus, DPP-4 inhibitors play a key role in the maintenance of glucose homeostasis through the potentiation of the action of GLP-1 and GIP. Incretin effects are impaired in patients with type 2 diabetes mellitus (T2DM), despite a similar incretin hormone response to healthy controls after increasing oral glucose loads, emphasizing the necessity for the supplementation of exogenous incretins or an enhanced action of endogenous incretins. ${ }^{9}$

Linagliptin, based on a xanthine scaffold structure, not only shares many properties with other members of DPP-4 inhibitor class, such as low risk of hypoglycemia and weight neutrality, but also has a special pharmacokinetic (PK) profile that is clinically relevant. ${ }^{10}$ Unlike other DPP-4 inhibitors, linagliptin is predominantly excreted unchanged in feces, with no necessity of dose adjustment in the case of renal impairment since renal excretion only makes a minor contribution to the overall elimination (primarily nonrenalclearance pathway). Extensive binding with plasma protein and a long terminal half-life make once-daily oral administration possible. ${ }^{11}$ Coadministration with some other antidiabetic and cardiovascular drugs results in low potential of drugdrug interaction. ${ }^{12}$ Considering the unique characteristics of linagliptin, we will here review the updated publications about the usage of linagliptin in Asians.

\section{Pharmacokinetics and pharmacodynamics}

In a Phase II, randomized, double-blind, placebo-controlled study, 72 Japanese T2DM patients were assigned to receive placebo or linagliptin $0.5 \mathrm{mg}, 2.5 \mathrm{mg}$, or $10 \mathrm{mg}$ once daily for consecutive 28 days according to the proportion of $1: 1: 1: 1$. Linagliptin was rapidly absorbed with a median $t_{\max , \mathrm{ss}}$ of $\sim 1.5$ hours across all dose ranges. At steady state, neither $\mathrm{AUC}_{\mathrm{ss}}$ nor $C_{\text {max,ss }}$, parameters of systemic linagliptin exposure did increase dose-proportionally across all dose ranges, and this was a reflection of the unique nonlinear PK profile of linagliptin. Linagliptin was widely distributed in the body, as the geometric mean (gMean) of apparent volume of distribution $\left(V_{\mathrm{d}} / F_{\mathrm{R}, \mathrm{ss}}\right)$ was from $4,090 \mathrm{~L}$ for the $0.5 \mathrm{mg}$ dose to $21,200 \mathrm{~L}$ for the $10 \mathrm{mg}$ dose at steady state. The terminal half-life was long enough (223-260 hours) for sustained suppression of DPP-4. In contrast, the accumulation half-life was short (10-38.5 hours), resulting in rapid attainment of steady state. Steady-state AUC ranged from 2.9-fold for $0.5 \mathrm{mg}$ dose to 1.2 -fold for $10 \mathrm{mg}$ dose greater than after a single dose, indicating little accumulation. Apparent clearance $\left(\mathrm{CL} / F_{\mathrm{R}, \mathrm{ss}}\right)$ and renal clearance $\left(\mathrm{CL}_{\mathrm{R}, \mathrm{ss}}\right)$ after oral administration increased with dose. Even so, renal excretion only played a minor part in the overall elimination of linagliptin, with steady-state urinary excretion not exceeding $7 \%$ of the administrated dose. ${ }^{13}$ These PK parameters were comparable to that of linagliptin in healthy Japanese and Chinese subjects and Caucasian T2DM patients as shown in Table 1. ${ }^{14-16}$ Consistently, the prescribing information indicates no dose adjustments given the fact that race has no clinically relevant influence on the PK of linagliptin, regardless of Caucasian, Hispanic, Blacks, and Asians. ${ }^{17}$

Plasma protein binding was extensive and in a concentration-dependent manner. An in vitro experiment had shown that the protein-binding percentage of linagliptin decreased with increasing concentration (from $\sim 99 \%$ at a concentration $<1 \mathrm{nM}$ to $70 \%-80 \%$ at a concentration $>100 \mathrm{nM}$ ), as a result of the high affinity but easily saturated binding capacity to plasma DPP-4 at therapeutic concentrations. ${ }^{18}$ Based on the nonlinear PK and concentration dependency of plasma protein binding, researchers had developed a two-compartment model, with linagliptin distributed in the central and peripheral compartments. ${ }^{19,20}$ In a previous study, the 28-day treatment of multiple-dose linagliptin produced maximal inhibition of DPP-4 by $66.7 \%, 89.6 \%$, and $92.9 \%$ for $0.5 \mathrm{mg}, 2.5 \mathrm{mg}$, and $10 \mathrm{mg}$ dose groups, respectively. DPP-4 inhibition at 24-hour postdose was 46\%, 78\%, and $90 \%$ for $0.5 \mathrm{mg}, 2.5 \mathrm{mg}$, and $10 \mathrm{mg}$ dose groups, respectively. ${ }^{13}$ Typically, DPP-4 inhibition $\geq 80 \%>24$ hours is therapeutically required to achieve a maximal hypoglycemic effect. ${ }^{21}$ However, in this study, there were no data about the $\mathrm{PK} /$ pharmacodynamics (PD) of linagliptin $5 \mathrm{mg}$ once daily in Japanese T2DM patients. With these experimental data, researchers simulated the plasma DPP-4 inhibition of linagliptin $5 \mathrm{mg}$ once daily in a well-established and carefully verified target-mediated drug disposition model, suggesting that $5 \mathrm{mg}$ linagliptin once daily resulted in $84.2 \%$ DPP-4 inhibition at 24 hours after the last dose, which was therapeutically meaningful. ${ }^{19}$ Similarly, data from 56 healthy male Japanese subjects participating in a 12-day Phase I, double-blind, placebo-controlled study indicated that after multiple doses, $\geq 80 \%$ DPP-4 inhibition after 24-hour dosing interval was achieved in 33\%,100\%,100\% of subjects in the linagliptin $2.5 \mathrm{mg}, 5 \mathrm{mg}$, and $10 \mathrm{mg}$ once-daily group, with maximal DPP-4 inhibition being 92\%-93\% for all 


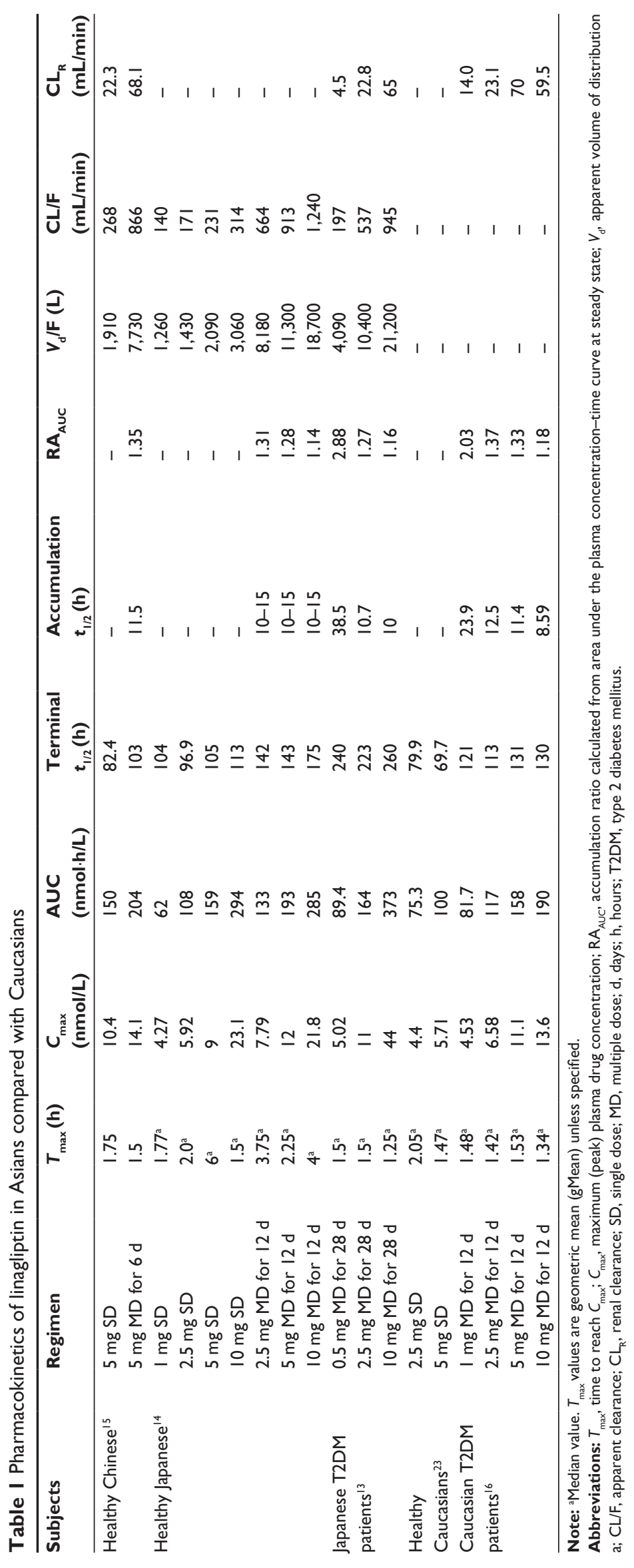


dose groups. These PD parameters were comparable to that of Caucasian T2DM patients. ${ }^{16}$

Linagliptin is the most potent DPP-4 inhibitor currently available in the market. Under the identical in vitro experimental conditions, linagliptin produced an $\mathrm{IC}_{50}$ of approximately $1 \mathrm{nM}$, compared with sitagliptin of $19 \mathrm{nM}$, alogliptin of $24 \mathrm{nM}$, saxagliptin of $50 \mathrm{nM}$, and vildagliptin of $60 \mathrm{nM}$. As a competitive inhibitor, linagliptin had a $K_{\mathrm{i}}$ of $1 \mathrm{nM}$. Moreover, linagliptin reversibly but tightly binds DPP-4 enzyme, with approximately tenfold slower dissociation rate from DPP-4 than another DPP-4 competitive inhibitor, vildagliptin, resulting in prolonged DPP-4 inhibition even if the free fraction had been cleared from the circulation. ${ }^{22}$ Both in healthy and in type 2 diabetic Japanese patients, $50 \%$ and $80 \%$ inhibition of maximal DPP-4 inhibition occurred at a concentration range of 2-4 nmol/L and 4-6 nmol/L, respectively, comparable to the data in Caucasians. ${ }^{13,14,23}$ Besides its potency, linagliptin is a highly selective DPP-4 inhibitor, being $\geq 10,000$-fold more selective for DPP-4 compared to DPP-8 and DPP-9 in vitro. The selectivity, to some extent, ensures the safety of the treatment, given the detrimental effect of DPP-8 and DPP-9 inhibition on multiorgans and immune system observed in animals. ${ }^{22}$

With its primarily nonrenal elimination route and potency, which means easily saturable binding to its target DPP-4 enzyme at low doses, it seems that linagliptin is unlikely to accumulate even in T2DM patients with renal impairment. In a 24-week, multicenter, Phase III study, nearly half of participants were Asians. No statistical significance was reported in the mean linagliptin trough concentrations over time between patients with normal renal function (estimated glomerular filtration rate $[\mathrm{eGFR}] \geq 90 \mathrm{~mL} / \mathrm{min} / 1.73 \mathrm{~m}^{2}$ ) and those with mildly (eGFR 60 to $<90 \mathrm{~mL} / \mathrm{min} / 1.73 \mathrm{~m}^{2}$ ) or moderately (eGFR 30 to $<60 \mathrm{~mL} / \mathrm{min} / 1.73 \mathrm{~m}^{2}$ ) impaired renal function: $8.0 \pm 7.3 \mathrm{nmol} / \mathrm{L}, 8.0 \pm 7.6 \mathrm{nmol} / \mathrm{L}$, and $6.6 \pm 1.8 \mathrm{nmol} / \mathrm{L}$, respectively. ${ }^{24}$

\section{Efficacy \\ Monotherapy}

In a multicenter, randomized, double-blind, placebocontrolled, Phase III study comparing linagliptin (5 mg once daily, $n=336)$ with placebo $(n=167), 46.1 \%$ of participants with T2DM had an Asian derivation. A total of 24 weeks of intervention resulted in an adjusted mean change in $\mathrm{HbA}_{1 \mathrm{c}}$ of $-0.69 \%(P<0.0001)$, favoring linagliptin over placebo, with no significant difference between Asian and Caucasian, the two main population recruited. ${ }^{24}$

Similarly, in a randomized, double-blind, parallel-group, Phase IIb/III study carried out in 561 Japanese T2DM patients, linagliptin $5 \mathrm{mg}$ and $10 \mathrm{mg}$ yielded placebocorrected adjusted mean reduction in $\mathrm{HbA}_{1 \mathrm{c}}$ of $-0.87 \%$ and $-0.88 \%$, respectively, at week 12 . Furthermore, linagliptin monotherapy also showed superiority in terms of glucose control when compared with another active comparator, voglibose $0.2 \mathrm{mg}$ tid, with adjusted mean treatment difference in $\mathrm{HbA}_{1 \mathrm{c}}$ of $-0.32 \%(P=0.0003)$ and $-0.39 \%$ $(P<0.0001)$ at week 26 for linagliptin $5 \mathrm{mg}$ and $10 \mathrm{mg}$ once daily. Reduction in proinsulin/insulin ratio reached statistical significance in both linagliptin $5 \mathrm{mg}$ and $10 \mathrm{mg}$ group. Linagliptin $5 \mathrm{mg}$ also showed a trend of nonsignificance to improve indexes of $\beta$-cell function, including fasting insulin, disposition index (DI), and homeostasis model assessment (HOMA) of IR. ${ }^{25}$

\section{Linagliptin as add-on therapy to one oral antidiabetic drug}

A 52-week, multicenter, open-label study evaluates the efficacy of linagliptin $5 \mathrm{mg}$ once daily as add-on therapy to one background oral antidiabetic drug (OAD), including biguanide, glinide, glitazone, sulphonylurea (SU), and $\alpha$-glucosidase inhibitor (A-GI), in 618 Japanese patients with T2DM inadequately controlled. Out of these, patients on SU (2:1) or A-GI (1:1) were randomized to linagliptin $5 \mathrm{mg}$ qd or metformin (twice or thrice daily, $\leq 2,250 \mathrm{mg}$ /day) (randomized group). Subjects on other background therapies receive linagliptin $5 \mathrm{mg}$ qd (nonrandomized group). Results showed that linagliptin therapy led to significant reduction in mean $\mathrm{HbA}_{1 \mathrm{c}}$ level of $-0.7 \%$ to $0.9 \%$ in nonrandomized group and that the hypoglycemic effect was comparable between linagliptin and metformin as add-on therapy to SU or A-GI, while once-daily regimen of linagliptin was more convenient. ${ }^{26}$

In a 2-year, randomized (1:1 in linagliptin: glimepiride), double-blind, parallel-group, Phase III study carried out in a large population of 1,551 T2DM patients inadequately controlled, including 12\% Asians, linagliptin $5 \mathrm{mg}$ once daily exhibited noninferiority to glimepiride $1-4 \mathrm{mg}$ once daily as add-on therapy to metformin, with change in adjusted mean $\mathrm{HbA}_{1 \mathrm{c}}$ being similar for linagliptin $(-0.16 \%)$ and glimepiride $(-0.36 \%)$. There was no ethnic difference in $\mathrm{HbA}_{1 \mathrm{c}}$ changes in each treatment group. Of note, linagliptin added to metformin was associated with significantly lower hypoglycemia rates, decreased body weight, and fewer cardiovascular events. ${ }^{27}$ Initial combination of linagliptin with metformin also substantially improved the glycemic control of patients with previously uncontrolled T2DM (including $32.5 \%$ Asians), and no interaction of significance between linagliptin and metformin was observed. ${ }^{28}$ 


\section{Linagliptin as add-on therapy to basal insulin with or without OADs}

In a multicenter, multinational, randomized (1:1 to linagliptin vs placebo), double-blind, Phase III study of linagliptin versus placebo as add-on therapy to basal insulin alone or in combination with one to two OADs (metformin and/or pioglitazone) in previously inadequately controlled patients with T2DM, $12.2 \%$ of the participants were Asians. The basal insulin remained unchanged for the first 24 weeks, and during this period, adjusted mean $\mathrm{HbA}_{1 \mathrm{c}}$ changed by $-0.58 \%$ for linagliptin and $0.07 \%$ for placebo (treatment difference $-0.65 \%$, $P<0.0001)$. The placebo-corrected change in fasting plasma glucose (FPG) was $-0.6 \mathrm{mmol} / \mathrm{L}(P<0.0001)$. After week 24 , titration of basal insulin was allowed for both groups to achieve a target FPG of $6.1 \mathrm{mmol} / \mathrm{L}$, which was more in line with the clinical practice. At week 52, the mean change in FPG of linagliptin-treated group was not significantly different from the placebo group, while the adjusted mean change in $\mathrm{HbA}_{1 \mathrm{c}}$ for linagliptin and placebo was $-0.48 \%$ and $0.05 \%$, respectively, leading to a treatment difference of $-0.53 \%$ ( $P<0.0001)$, which was maintained for up to 76 weeks. Of note, subgroup analysis found that variables such as renal function and age did not interact with treatment, while significant interaction $(P<0.1)$ was observed between treatment and other variables including race $(P=0.0603)$, which suggested that Asians were the greatest benefited population (placebo-adjusted mean change in $\mathrm{HbA}_{1 \mathrm{c}}$ was greatest for patients from Asian [-1\%] and of Asian origin $[-0.93 \%]) .{ }^{29}$ Although this phenomenon may be ascribed to the limited number of Asian subjects enrolled in this study, it still indicated the effectiveness of this drug in Asians.

\section{Linagliptin as add-on therapy to metformin plus pioglitazone}

A multicenter, randomized (2:1 to linagliptin vs placebo), double-blind, Phase III study carried out in 271 T2DM patients with inadequate glycemic control on metformin and pioglitazone (Asians accounted for 69\%), compared linagliptin vs placebo as add-on therapy to background regimen. After 24-week intervention, linagliptin significantly improved glycemic control, with a placebo-adjusted mean change in $\mathrm{HbA}_{1 \mathrm{c}}$ of $-0.57 \%(P<0.0001)$. The treatment difference between the groups was significant $(P<0.0001)$ at each evaluated time point and did not vary over time significantly. Subanalysis of $\mathrm{HbA}_{1 \mathrm{c}}$ changes by country revealed that India and Philippines, the two countries representing Asia in this study, achieved a significant reduction in $\mathrm{HbA}_{1 \mathrm{c}}$, with a placebo-adjusted change from baseline of $-0.9 \%$
$(P<0.0001)$ and $-0.8 \%(P=0.014)$, respectively. Linagliptin was also superior in reducing FPG and in the attainment of an $\mathrm{HbA}_{1 \mathrm{c}}$ target of $7 \%$ or $6.5 \%$. Moreover, HOMA- $\beta$ was $27 \%$ greater from baseline for linagliptin group vs placebo group $(P=0.0055)$, indicating that linagliptin may have a protective effect on $\beta$-cells. ${ }^{30}$

\section{Linagliptin as add-on therapy to metformin plus sulfonylurea}

In a prespecified Chinese patient subanalysis of a multinational, randomized, placebo-controlled clinical trial, linagliptin in triple combination with existing background regimen of metformin and SU ( $\mathrm{n}=144)$ led to significant improvement compared with placebo group $(n=48)$, consistent with the efficacy profile of the parent study. ${ }^{6,31}$ Placebo-corrected adjusted mean change in $\mathrm{HbA}_{1 \mathrm{c}}$ at week 24 for linagliptin was $-0.68 \%$ from a mean baseline of $8.1 \%$, comparable to $-0.62 \%$ reduction in the parent study. Placebo-corrected adjusted mean decrease in FPG at week 24 from baseline was $-1 \mathrm{mmol} / \mathrm{L}$ for linagliptin-treated group and $-0.7 \mathrm{mmol} / \mathrm{L}$ for the overall population. ${ }^{6,31}$ Moreover, significantly more patients achieved a target $\mathrm{HbA}_{1 \mathrm{c}}<7 \%$ in the linagliptin group $(29.8 \%$ vs $10.4 \%, P=0.01)$. The assessments of $\beta$-cell function and IR (HOMA- $\beta$ and HOMA-IR) showed a trend of improvements, but they did not show statistical significance. However, treatment difference in DI (adjusted mean change from baseline was $3.71 \mathrm{mmol} / \mathrm{L}$ vs $-2.83 \mathrm{mmol} / \mathrm{L}$ for linagliptin vs placebo, respectively) was statistically significant $(P=0.0007)$, suggestive of improved $\beta$-cell function.

Efficacy data were extracted from four multiethnic, randomized, double-blind, placebo-controlled Phase III studies of 24-week duration for pooled analysis of $5 \mathrm{mg}$ linagliptin once daily for Asian T2DM patients with uncontrolled glycemia (743 Asians in linagliptin group vs 286 Asians in placebo group) as monotherapy, as add-on therapy to metformin, as add-on therapy to metformin plus SU, and as initial therapy in combination with pioglitazone. Despite its post hoc nature, the analysis still provided evidence that linagliptin was efficacious in Asians, with a treatment difference at week 24 from baseline in $\mathrm{HbA}_{1 \mathrm{c}}$ of $-0.79 \%(P<0.0001)$, favoring linagliptin compared with placebo. ${ }^{32}$ The superiority of linagliptin over placebo was also reflected in significantly reducing FPG (placebo-corrected mean change was $-1 \mathrm{mmol} / \mathrm{L}, P<0.0001)$ and postprandial glucose (PPG) (placebo-corrected mean change was $-3.2 \mathrm{mmol} / \mathrm{L}, P=0.0002){ }^{32}$ These results showed that the efficacy of linagliptin in Asians was in consistence with that of the overall multiethnic population in the four parent studies. 
HOMA- $\beta$ and DI were also significantly improved, indicating a beneficial effect on $\beta$-cell function of linagliptin. ${ }^{32}$

Studies of linagliptin exclusively in Asian T2DM patients are listed in Table 2.

\section{Safety and tolerability}

Linagliptin has a safety and tolerability profile similar to that of placebo as monotherapy (at a dose of $5 \mathrm{mg}$ once daily ${ }^{24,25,33,34}$ or $10 \mathrm{mg}$ once daily $\mathrm{y}^{25,34}$ ), as add-on therapy to metformin, ${ }^{27,35}$ as initial regimen with pioglitazone, ${ }^{36}$ as add-on therapy to basal insulin, ${ }^{29}$ as add-on therapy to metformin plus pioglitazone in drug-related adverse events (AEs) (5 mg qd if not specified), ${ }^{30}$ with low rates of hypoglycemia comparable to other non-secretagogues such as metformin. ${ }^{26}$ And the majority of AEs were mild or moderate in intensity. A post hoc analysis for the safety assessment of linagliptin in Asian patients ${ }^{32}$ pooled safety data from ten placebo-controlled trials, which revealed that the overall incidence of AEs for linagliptin (as monotherapy or add-on therapy) vs placebo was similar (58\% vs $58.2 \%$ ), with $12.1 \%$ of patients in linagliptin-treated group vs $8.4 \%$ in placebo group experienced drug-related AEs. Drug-related gastrointestinal (GI) AEs and infections, commonly concerned in the DPP-4 inhibitor class, occurred in similar proportions $(2.2 \%$ vs $1.6 \%$, and $0.8 \%$ vs $0.5 \%$ ) in the linagliptin and placebo group, respectively. There was no report of heart failure or pancreatitis. Investigator-defined hypoglycemia was low for both linagliptin and placebo $(9.7 \%$ vs $5.3 \%) .{ }^{32}$ There was one caveat: the combination of SU and linagliptin led to an increased risk of hypoglycemia, ${ }^{6,26,32}$ so a dose reduction was needed for those who were in SU background to minimize the potential of hypoglycemia. There is a hypothesis that the uncoupling effect of SU could counteract the glucose-dependent action of linagliptin, with the underlying mechanisms remaining unclear.

In general, linagliptin provided a broad safety and tolerability profile, with low rates of hypoglycemia and stable maintenance of body weight. And the tolerability of linagliptin was sustained. ${ }^{34}$

\section{Safety in patients with renal impairment}

There is no direct design to confirm the renal safety of linagliptin in Asians. A pooled analysis, consisted of 1,029 patients from Asians for efficacy assessment, showed that linagliptin $5 \mathrm{mg}$ once daily was efficacious and well-tolerated. ${ }^{32}$ Despite one-third of subjects had mild-(eGFR $\geq 60$ to $<90 \mathrm{~mL} / \mathrm{min}$ ) to-moderate (eGFR $\geq 30$ to $<60 \mathrm{~mL} / \mathrm{min}$ ) renal impairment at baseline, no dose adjustment was made in consistence with

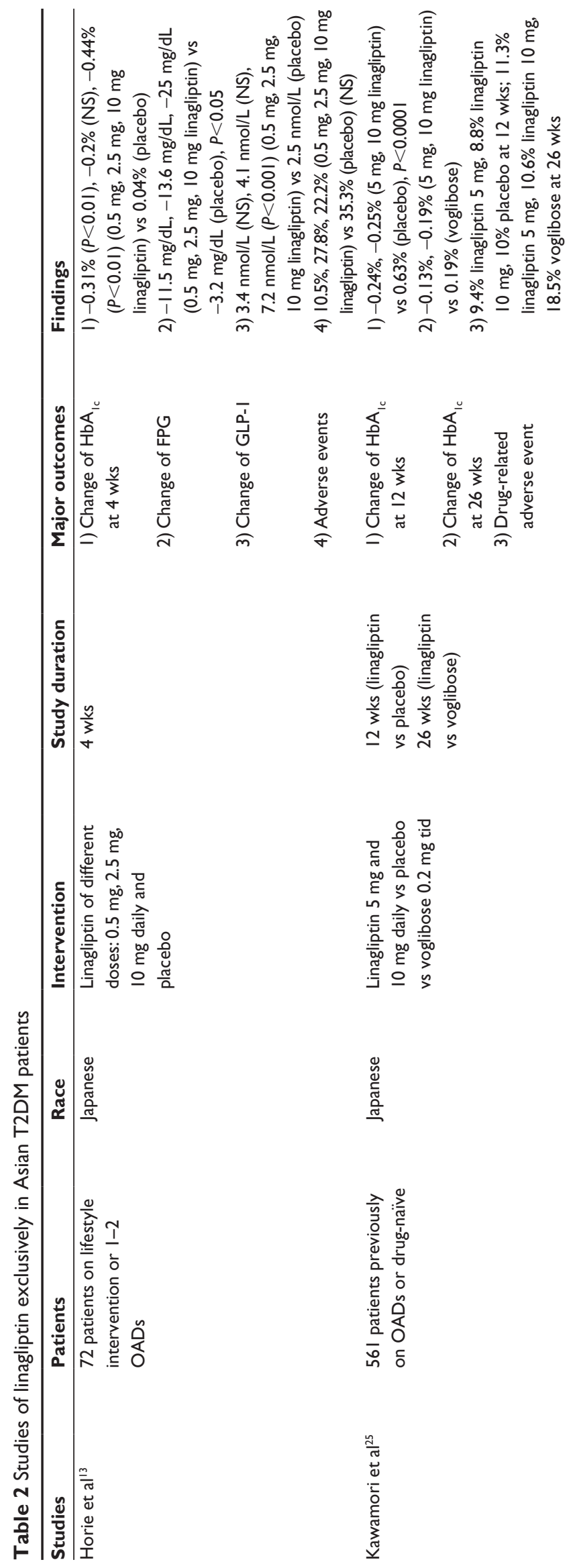


In addition, linagliptin as monotherapy or additional therapy had no clinically meaningful impact on clinical laboratory tests, physical examination, and vital signs.

\section{Discussion}

Worldwide, $77 \%$ of people affected with diabetes are now living in low- and middle-income countries, ${ }^{1}$ with People's Republic of China and India being the "top 2" countries that have the largest number of population with diabetes in 2013 and the same for the estimation in 2030.,43 Asian diabetic population is also continuing to rise sharply, driven by rapid nutrition transition associated with socioeconomic development, reduced physical activity related to sedentary lifestyle, genetic susceptibility, and other contributing factors..$^{3,44}$ Asian diet structure is unique in its refined rice and wheat basis, both with high glycemic index and dietary glycemic load values, leading to higher proportion of postchallenge hyperglycemia. ${ }^{45}$ Postprandial hyperglycemia was found to be associated with endothelial dysfunction, an early marker of cardiovascular complications. ${ }^{46,47}$ DPP-4 inhibitor class could effectively improve glucose homeostasis and is particularly effective in reducing PPG excursions in a glucose-dependent manner. ${ }^{48}$ As a xanthine-based DPP-4 inhibitor, linagliptin was proposed to have an antioxidative stress action in vitro at least partly via its inhibition of xanthine oxidase activity, ${ }^{49}$ which may bring about a protective effect on endothelia. Furthermore, not only protection against oxidative stress but also improvement of cardiomyocyte ultrastructure was observed in animal models. ${ }^{50}$ Correspondingly, it was reported that linagliptin may have cardiovascular effects. ${ }^{51}$

In contrast with Caucasians, decline in $\beta$-cell function occurred early and may be the primary abnormality for Asian population at risk of or with T2DM. ${ }^{44}$ Linagliptin had shown protective effect of $\beta$-cells, in part attributable to amelioration of gluco- and lipotoxicity in Asians. In addition, animal and ex vivo experiments demonstrated that linagliptin could reduce lymphocyte insulinitis, restore proliferation, and inhibit apoptosis of $\beta$-cells via suppression of oxidative stress and proinflammatory cytokine responses, ${ }^{52}$ which may also be a part of the underlying mechanisms contributing to the $\beta$-cell-protecting effect. Consistently, it has been proposed that DPP-4 inhibitors were particularly efficacious for Asians compared with other ethnic groups. ${ }^{53}$ Moreover, preclinical experiments had demonstrated the immunomodulatory effects of DPP-4 inhibitors through both GLP-1-dependent and -independent pathways, ${ }^{54,55}$ in favor of the usage of DPP-4 inhibitors in type 2 diabetes since immune dysfunctions were also present in T2DM. ${ }^{56}$ Therefore, the $\beta$-cell-preserving effect of DPP-4 inhibitors ${ }^{57}$ was another promising prospect for the treatment of T2DM. This is an area requiring further investigation since the hypothesis was based on animal or in vitro studies and biomarkers.

As a potent DPP-4 inhibitor, the $\mathrm{HbA}_{1 \mathrm{c}}$-lowering efficacy of linagliptin $5 \mathrm{mg}$ qd was comparable to sitagliptin $100 \mathrm{mg}$ $\mathrm{qd},{ }^{58}$ vildagliptin $50 \mathrm{mg}$ bid, ${ }^{59}$ and saxagliptin $5 \mathrm{mg} \mathrm{qd} d^{60,61}$ in Asians as monotherapy or add-on therapy to metformin, despite the lowest bioavailability of $\sim 30 \%$ as compared with sitagliptin $87 \%$, vildagliptin $85 \%,{ }^{10}$ and saxagliptin $50 \%$. ${ }^{62}$ However, there is still a scarcity of head-to-head comparisons of all DPP-4 inhibitors in Asian diabetic patients, since an identical design in a more homogenous population will provide more compelling evidence.

Renal insufficiency results in reduced clearance of hypoglycemic agents and impaired kidney glyconeogenesis. In addition, diabetic patients with renal dysfunctions are often elderly and concomitantly complicated with diabetic neuropathy and/or cognitive disorder, and these factors act together to put the patients in a greater risk of hypoglycemia. Furthermore, renal failure continues to increase despite strict glucose and blood pressure management strategy, including renin-angiotensin system blocking with a role of albuminuria lowering and renoprotection. ${ }^{63}$ Thus, novel treatments aimed to maintain and even improve kidney function are in urgent need. Different from other DPP-4 inhibitors, linagliptin is excreted primarily through a nonrenal pathway in unchanged form, together with the PK property of little accumulation, making dose adjustment unnecessary even in the case of renal insufficiency. Race has no impact on PK and PD of linagliptin in diabetic patients with or without nephropathy. ${ }^{17,38,64}$ Clinical studies confirmed that renal impairment had no clinically relevant impact on PK and PD of linagliptin in patients with diabetes including Asians. ${ }^{24}$ Linagliptin was efficacious, safe, and well-tolerated in Asian patients with T2DM and various degrees of renal impairment, without the AEs of increased hypoglycemia, fluid retention, weight gain, or deterioration of renal functions. ${ }^{25,26,37,39}$ It was indicated that linagliptin had an additional albuminuria-lowering effect, on the basis of preexisting renin-angiotensin-aldosterone system inhibitors, in T2DM patients with albuminuria (urinary albumin-to-creatinine ratio of $30-3,000 \mathrm{mg} / \mathrm{g}$ ), independent of alterations in plasma glucose and blood pressure. ${ }^{65}$ Preclinical experiments had demonstrated that animals treated with linagliptin manifested a mitigation of kidney fibrosis, associated with the suppression of 
endothelial-to-mesenchymal transition, without an alteration of glucose level. ${ }^{66}$ Supportive evidence included an in vitro study that showed that linagliptin inhibited the activation and release of TGF- $\beta$, followed by suppression of related profibrotic downstream pathways. ${ }^{67}$ Moreover, significant improvement of albuminuria, reduction of advanced glycation end products-receptor (AGE-RAGE)-induced oxidative stress and intercellular adhesion molecule-1 (ICAM-1) mRNA level in the kidney, and amelioration of glomerular lymphocyte infiltration were observed in linagliptin-treated rats. ${ }^{68}$ However, whether or not it is the same situation in human still needs further exploration. And studies carried out exclusively in Asian patients with varying degrees of renal dysfunction or in comparison with other ethnic group aimed at comparative PK and PD are needed.

Suppression of the enzymatic degradation of incretins by DPP-4 inhibitors could potentiate the physiological action of GLP-1 and GIP. Of note, unlike GLP-1, the suppressive effect of DPP-4 inhibitors on postprandial glucagon secretion is quite weak and of short duration. ${ }^{8}$ Moreover, DPP-4 inhibitors have no significant impact on GI mobility and are weight neutral, ${ }^{69}$ indicating that DPP-4 inhibitors do not regulate glucose homeostasis via exactly the same mechanisms as native incretins. In addition, the subsets of immune cells regulated by GLP-1 and DPP-4 inhibitors were not uniformly identical. ${ }^{54}$ It was also speculated that the increase in GLP-1 concentration caused by DPP-4 inhibition was insufficient to explain the hypoglycemic effect, and possibly by the same token, DPP-4 inhibitors had no significant impact on GI mobility and body weight. ${ }^{8}$ More researches are needed for the specific mechanisms.

With the progression of the disease, the patients fail to achieve the glycemic control target on monotherapy (usually metformin) need to switch to dual therapy and even triple therapy of OADs (with metformin being the cornerstone) before the initiation of insulin treatment. Incretin mimetic and DPP-4 inhibitors have similar antidiabetic efficacy and a broader safety and tolerability profile when compared with other OADs such as SU and thiazolidinediones. ${ }^{70}$ Furthermore, linagliptin was demonstrated to be efficacious and safe in patients for whom metformin was contradicted owing to renal impairment or intolerability. ${ }^{33}$

\section{Conclusion}

In conclusion, similar to that in Caucasians, linagliptin has a nonlinear PK with the characteristics of rapid attainment of steady state, little accumulation, primarily nonrenal route of elimination, long-terminal half-life, and sustained inhibition of DPP-4 enzyme in the Asians. Linagliptin was efficacious and well-tolerated in Asian T2DM patients, comparable to that in Caucasians. However, most conclusions are derived from pooled data of multiracial studies or post hoc comparison of data in different races. Therefore, more researches carried out exclusively in Asian patients or for head-to-head comparison with other ethnic groups are needed.

\section{Acknowledgments}

Professor Zhi-guang Zhou was supported by the grant of National Clinical Research Center for Metabolic Disease (2013BAI09B12). Dr Yu-fei Xiang was supported by the European Foundation for the Study of Diabetes (EFSD) China Diabetes Society (CDS)-Lilly Fellowship (2013), the Shenhua Yuying Talent plan of Central South University (2014), and the National Natural Science Foundation of China (Grant no 81400817). Dr Chu-qing Cao was supported by the Fundamental Research Funds for the Central Universities of Central South University (2015zzts306).

\section{Disclosure}

The authors report no conflicts of interest in this work.

\section{References}

1. International Diabetes Federation. Key findings 2014. Diabetes Atlas. 6th ed. Brussels: International Diabetes Federation; 2014.

2. Wild S, Roglic G, Green A, Sicree R, King H. Global prevalence of diabetes: estimates for the year 2000 and projections for 2030. Diabetes Care. 2004;27(5):1047-1053.

3. Chan JC, Malik V, Jia W, et al. Diabetes in Asia: epidemiology, risk factors, and pathophysiology. JAMA. 2009;301(20):2129-2140.

4. Karter AJ, Ferrara A, Liu JY, Moffet HH, Ackerson LM, Selby JV. Ethnic disparities in diabetic complications in an insured population. JAMA. 2002;287(19):2519-2527.

5. Flynn C, Bakris GL. Noninsulin glucose-lowering agents for the treatment of patients on dialysis. Nat Rev Nephrol. 2013;9(3): 147-153.

6. Owens DR, Swallow R, Dugi KA, Woerle HJ. Efficacy and safety of linagliptin in persons with type 2 diabetes inadequately controlled by a combination of metformin and sulphonylurea: a 24-week randomized study. Diabet Med. 2011;28(11):1352-1361.

7. Ghazi T, Rink L, Sherr JL, Herold KC. Acute metabolic effects of exenatide in patients with type 1 diabetes with and without residual insulin to oral and intravenous glucose challenges. Diabetes Care. 2014;37(1): 210-216.

8. Chia CW, Egan JM. Incretin-based therapies in type 2 diabetes mellitus. J Clin Endocrinol Metab. 2008;93(10):3703-3716.

9. Bagger JI, Knop FK, Lund A, Vestergaard H, Holst JJ, Vilsboll T. Impaired regulation of the incretin effect in patients with type 2 diabetes. J Clin Endocrinol Metab. 2011;96(3):737-745.

10. Agrawal R, Jain P, Dikshit SN. Linagliptin: a novel methylxanthin based approved dipeptidyl peptidase-4 inhibitor. Curr Drug Targets. 2012;13(7):970-983.

11. Scheen AJ. Pharmacokinetics of dipeptidylpeptidase-4 inhibitors. Diabetes Obes Metab. 2010;12(8):648-658.

12. Scott LJ. Linagliptin: in type 2 diabetes mellitus. Drugs. 2011;71(5): 611-624. 
13. Horie $\mathrm{Y}$, Kanada S, Watada H, et al. Pharmacokinetic, pharmacodynamic, and tolerability profiles of the dipeptidyl peptidase-4 inhibitor linagliptin: a 4-week multicenter, randomized, double-blind, placebo-controlled phase IIa study in Japanese type 2 diabetes patients. Clin Ther. 2011;33(7):973-989.

14. Sarashina A, Sesoko S, Nakashima M, et al. Linagliptin, a dipeptidyl peptidase- 4 inhibitor in development for the treatment of type 2 diabetes mellitus: a phase I, randomized, double-blind, placebo-controlled trial of single and multiple escalating doses in healthy adult male Japanese subjects. Clin Ther. 2010;32(6):1188-1204.

15. Friedrich C, Shi X, Zeng P, Ring A, Woerle H, Patel S. Pharmacokinetics of single and multiple oral doses of $5 \mathrm{mg}$ linagliptin in healthy Chinese volunteers. Int J Clin Pharmacol Ther. 2012;50:889-895.

16. Heise T, Graefe-Mody EU, Huttner S, Ring A, Trommeshauser D, Dugi KA. Pharmacokinetics, pharmacodynamics and tolerability of multiple oral doses of linagliptin, a dipeptidyl peptidase-4 inhibitor in male type 2 diabetes patients. Diabetes Obes Metab. 2009;11(8):786-794.

17. Tradjenta ${ }^{\circledR}$ (linagliptin) tablets. Highlights of Prescribing Information; 2013.

18. Fuchs H, Tillement JP, Urien S, Greischel A, Roth W. Concentrationdependent plasma protein binding of the novel dipeptidyl peptidase 4 inhibitor BI 1356 due to saturable binding to its target in plasma of mice, rats and humans. J Pharm Pharmacol. 2009;61(1):55-62.

19. Tadayasu Y, Sarashina A, Tsuda Y, et al. Population pharmacokinetic/ pharmacodynamic analysis of the DPP-4 inhibitor linagliptin in Japanese patients with type 2 diabetes mellitus. J Pharm Pharm Sci. 2013; 16(5):708-721.

20. Retlich S, Duval V, Graefe-Mody U, Jaehde U, Staab A. Impact of target-mediated drug disposition on linagliptin pharmacokinetics and DPP-4 inhibition in type 2 diabetic patients. J Clin Pharmacol. 2010;50(8):873-885.

21. Herman GA, Stevens C, Van Dyck K, et al. Pharmacokinetics and pharmacodynamics of sitagliptin, an inhibitor of dipeptidyl peptidase IV, in healthy subjects: results from two randomized, double-blind, placebo-controlled studies with single oral doses. Clin Pharmacol Ther. 2005;78(6):675-688.

22. Thomas L, Eckhardt M, Langkopf E, Tadayyon M, Himmelsbach F, Mark M. (R)-8-(3-amino-piperidin-1-yl)-7-but-2-ynyl-3-methyl-1-(4methyl-quinazolin-2-ylm ethyl)-3,7-dihydro-purine-2,6-dione (BI 1356), a novel xanthine-based dipeptidyl peptidase 4 inhibitor, has a superior potency and longer duration of action compared with other dipeptidyl peptidase-4 inhibitors. J Pharmacol Exp Ther. 2008;325(1):175-182.

23. Huttner S, Graefe-Mody EU, Withopf B, Ring A, Dugi KA. Safety, tolerability, pharmacokinetics, and pharmacodynamics of single oral doses of BI 1356, an inhibitor of dipeptidyl peptidase 4, in healthy male volunteers. J Clin Pharmacol. 2008;48(10):1171-1178.

24. Del PS, Barnett AH, Huisman H, Neubacher D, Woerle HJ, Dugi KA. Effect of linagliptin monotherapy on glycaemic control and markers of beta-cell function in patients with inadequately controlled type 2 diabetes: a randomized controlled trial. Diabetes Obes Metab. 2011;13(3):258-267.

25. Kawamori R, Inagaki N, Araki E, et al. Linagliptin monotherapy provides superior glycaemic control versus placebo or voglibose with comparable safety in Japanese patients with type 2 diabetes: a randomized, placebo and active comparator-controlled, double-blind study. Diabetes Obes Metab. 2012;14(4):348-357.

26. Inagaki $\mathrm{N}$, Watada $\mathrm{H}$, Murai $\mathrm{M}$, et al. Linagliptin provides effective, well-tolerated add-on therapy to pre-existing oral antidiabetic therapy over 1 year in Japanese patients with type 2 diabetes. Diabetes Obes Metab. 2013;15(9):833-843.

27. Gallwitz B, Rosenstock J, Rauch T, et al. 2-year efficacy and safety of linagliptin compared with glimepiride in patients with type 2 diabetes inadequately controlled on metformin: a randomised, double-blind, non-inferiority trial. Lancet. 2012;380(9840):475-483.

28. Haak T, Meinicke T, Jones R, Weber S, von Eynatten M, Woerle HJ. Initial combination of linagliptin and metformin improves glycaemic control in type 2 diabetes: a randomized, double-blind, placebocontrolled study. Diabetes Obes Metab. 2012;14(6):565-574.
29. Yki-Järvinen H, Rosenstock J, Durán-Garcia S, et al. Effects of adding linagliptin to basal insulin regimen for inadequately controlled type 2 diabetes: a $>/=52$-week randomized, double-blind study. Diabetes Care. 2013;36(12):3875-3881.

30. Bajaj M, Gilman R, Patel S, Kempthorne-Rawson J, Lewis-D'Agostino D, Woerle HJ. Linagliptin improved glycaemic control without weight gain or hypoglycaemia in patients with type 2 diabetes inadequately controlled by a combination of metformin and pioglitazone: a 24-week randomized, double-blind study. Diabet Med. 2014;31(12):1505-1514.

31. Zeng Z, Yang JK, Tong N, et al. Efficacy and safety of linagliptin added to metformin and sulphonylurea in Chinese patients with type 2 diabetes: a sub-analysis of data from a randomised clinical trial. Curr Med Res Opin. 2013;29(8):921-929.

32. Zeng Z, Choi DS, Mohan V, et al. Efficacy and safety of linagliptin as monotherapy or add-on treatment in Asian patients with suboptimal glycemic control: a pooled analysis. Curr Med Res Opin. 2015;31(1):99-106.

33. Barnett AH, Patel S, Harper R, et al. Linagliptin monotherapy in type 2 diabetes patients for whom metformin is inappropriate: an 18-week randomized, double-blind, placebo-controlled phase III trial with a 34-week active-controlled extension. Diabetes Obes Metab. 2012;14(12): 1145-1154.

34. Araki E, Kawamori R, Inagaki N, et al. Long-term safety of linagliptin monotherapy in Japanese patients with type 2 diabetes. Diabetes Obes Metab. 2013;15(4):364-371.

35. Taskinen MR, Rosenstock J, Tamminen I, et al. Safety and efficacy of linagliptin as add-on therapy to metformin in patients with type 2 diabetes: a randomized, double-blind, placebo-controlled study. Diabetes Obes Metab. 2011;13(1):65-74

36. Gomis R, Espadero RM, Jones R, Woerle HJ, Dugi KA. Efficacy and safety of initial combination therapy with linagliptin and pioglitazone in patients with inadequately controlled type 2 diabetes: a randomized, double-blind, placebo-controlled study. Diabetes Obes Metab. 2011;13(7):653-661.

37. Ito $\mathrm{H}, \mathrm{Abe} \mathrm{M}$, Antoku $\mathrm{S}$, et al. Comparison of the antidiabetic effects of linagliptin among groups with a normal renal function and a mild or severe renal impairment - retrospective observation study of Japanese patients with type 2 diabetes mellitus. Expert Opin Pharmacother. 2015;16(3):289-296.

38. Friedrich C, Emser A, Woerle HJ, Graefe-Mody U. Renal impairment has no clinically relevant effect on the long-term exposure of linagliptin in patients with type 2 diabetes. Am J Ther. 2013;20(6):618-621.

39. von Eynatten M, Gong Y, Emser A, Woerle HJ. Efficacy and safety of linagliptin in type 2 diabetes subjects at high risk for renal and cardiovascular disease: a pooled analysis of six phase III clinical trials. Cardiovasc Diabetol. 2013;12:60.

40. Sanyal D, Gupta S, Das P. A retrospective study evaluating efficacy and safety of linagliptin in treatment of NODAT (in renal transplant recipients) in a real world setting. Indian J Endocrinol Metab. 2013; 17(supp1 1):S203-S205.

41. Graefe-Mody U, Rose P, Retlich S, et al. Pharmacokinetics of linagliptin in subjects with hepatic impairment. Br J Clin Pharmacol. 2012; 74(1):75-85.

42. Lewin AJ, Arvay L, Liu D, Patel S, von Eynatten M, Woerle HJ. Efficacy and tolerability of linagliptin added to a sulfonylurea regimen in patients with inadequately controlled type 2 diabetes mellitus: an 18-week, multicenter, randomized, double-blind, placebo-controlled trial. Clin Ther. 2012;34(9):1909-1919

43. International Diabetes Federation. Diabetes Atlas. 6th ed. Brussels: International Diabetes Federation; 2013.

44. Gujral UP, Pradeepa R, Weber MB, Narayan KM, Mohan V. Type 2 diabetes in South Asians: similarities and differences with white Caucasian and other populations. Ann N Y Acad Sci. 2013;1281:51-63.

45. DECODA Study Group; International Diabetes Epidemiology Group. Cardiovascular risk profile assessment in glucose-intolerant Asian individuals - an evaluation of the World Health Organization two-step strategy: the DECODA Study (Diabetes Epidemiology: Collaborative Analysis of Diagnostic Criteria in Asia). Diabet Med. 2002;19(7):549-557. 
46. Ceriello A, Cavarape A, Martinelli L, et al. The post-prandial state in Type 2 diabetes and endothelial dysfunction: effects of insulin aspart. Diabet Med. 2004;21(2):171-175.

47. Stirban AO, Tschoepe D. Cardiovascular complications in diabetes: targets and interventions. Diabetes Care. 2008;31(suppl 2):S215-S221.

48. DeFronzo RA, Okerson T, Viswanathan P, Guan X, Holcombe JH, MacConell L. Effects of exenatide versus sitagliptin on postprandial glucose, insulin and glucagon secretion, gastric emptying, and caloric intake: a randomized, cross-over study. Curr Med Res Opin. 2008;24(10):2943-2952.

49. Yamagishi S, Ishibashi Y, Ojima A, Sugiura T, Matsui T. Linagliptin, a xanthine-based dipeptidyl peptidase-4 inhibitor, decreases serum uric acid levels in type 2 diabetic patients partly by suppressing xanthine oxidase activity. Int J Cardiol. 2014;176(2):550-552.

50. Aroor AR, Sowers JR, Bender SB, et al. Dipeptidylpeptidase inhibition is associated with improvement in blood pressure and diastolic function in insulin-resistant male Zucker obese rats. Endocrinology. 2013;154(7):2501-2513

51. Johansen OE, Neubacher D, von Eynatten M, Patel S, Woerle HJ. Cardiovascular safety with linagliptin in patients with type 2 diabetes mellitus: a pre-specified, prospective, and adjudicated meta-analysis of a phase 3 programme. Cardiovasc Diabetol. 2012;11:3.

52. Jelsing J, Vrang N, van Witteloostuijn SB, Mark M, Klein T. The DPP4 inhibitor linagliptin delays the onset of diabetes and preserves beta-cell mass in non-obese diabetic mice. J Endocrinol. 2012;214(3):381-387.

53. Kim YG, Hahn S, Oh TJ, Kwak SH, Park KS, Cho YM. Differences in the glucose-lowering efficacy of dipeptidyl peptidase-4 inhibitors between Asians and non-Asians: a systematic review and meta-analysis. Diabetologia. 2013;56(4):696-708.

54. Kim SJ, Nian C, McIntosh CH. Sitagliptin (MK0431) inhibition of dipeptidyl peptidase IV decreases nonobese diabetic mouse CD4+ T-cell migration through incretin-dependent and -independent pathways. Diabetes. 2010;59(7):1739-1750.

55. Tian L, Gao J, Hao J, et al. Reversal of new-onset diabetes through modulating inflammation and stimulating beta-cell replication in nonobese diabetic mice by a dipeptidyl peptidase IV inhibitor. Endocrinology. 2010;151(7):3049-3060.

56. Sarikonda G, Pettus J, Phatak S, et al. CD8 T-cell reactivity to islet antigens is unique to type 1 while CD4 T-cell reactivity exists in both type 1 and type 2 diabetes. J Autoimmun. 2014;50:77-82.

57. Shah P, Ardestani A, Dharmadhikari G, et al. The DPP-4 inhibitor linagliptin restores beta-cell function and survival in human isolated islets through GLP-1 stabilization. J Clin Endocrinol Metab. 2013;98(7):E1163-E1172.
58. Yang W, Guan Y, Shentu Y, et al. The addition of sitagliptin to ongoing metformin therapy significantly improves glycemic control in Chinese patients with type 2 diabetes. J Diabetes. 2012;4(3):227-237.

59. Pan C, Xing X, Han P, et al; Institution Investigators. Efficacy and tolerability of vildagliptin as add-on therapy to metformin in Chinese patients with type 2 diabetes mellitus. Diabetes Obes Metab. 2012;14(8): 737-744.

60. Yang W, Pan CY, Tou C, Zhao J, Gause-Nilsson I. Efficacy and safety of saxagliptin added to metformin in Asian people with type 2 diabetes mellitus: a randomized controlled trial. Diabetes Res Clin Pract. 2011;94(2):217-224.

61. Pan CY, Yang W, Tou C, Gause-Nilsson I, Zhao J. Efficacy and safety of saxagliptin in drug-naive Asian patients with type 2 diabetes mellitus: a randomized controlled trial. Diabetes Metab Res Rev. 2012;28(3):268-275.

62. Boulton DW, Kasichayanula S, Keung CF, et al. Simultaneous oral therapeutic and intravenous (1)(4)C-microdoses to determine the absolute oral bioavailability of saxagliptin and dapagliflozin. Br J Clin Pharmacol. 2013;75(3):763-768.

63. Panchapakesan U, Pollock CA. DPP-4 inhibitors-renoprotection in diabetic nephropathy? Diabetes. 2014;63(6):1829-1830.

64. Graefe-Mody U, Friedrich C, Port A, et al. Effect of renal impairment on the pharmacokinetics of the dipeptidyl peptidase-4 inhibitor linagliptin (*). Diabetes Obes Metab. 2011;13(10):939-946.

65. Groop PH, Cooper ME, Perkovic V, Emser A, Woerle HJ, von Eynatten M. Linagliptin lowers albuminuria on top of recommended standard treatment in patients with type 2 diabetes and renal dysfunction. Diabetes Care. 2013;36(11):3460-3468.

66. Kanasaki K, Shi S, Kanasaki M, et al. Linagliptin-mediated DPP-4 inhibition ameliorates kidney fibrosis in streptozotocin-induced diabetic mice by inhibiting endothelial-to-mesenchymal transition in a therapeutic regimen. Diabetes. 2014;63(6):2120-2131.

67. Panchapakesan U, Gross S, Komala MG, Pegg K, Pollock CA. DPP4 inhibition in human kidney proximal tubular cells - renoprotection in diabetic nephropathy? J Diabetes Metab. 2013;S9:007.

68. Nakashima S, Matsui T, Takeuchi M, Yamagishi SI. Linagliptin blocks renal damage in type 1 diabetic rats by suppressing advanced glycation end products-receptor axis. Horm Metab Res. 2014;46(10): 717-721.

69. Lovshin JA, Drucker DJ. Incretin-based therapies for type 2 diabetes mellitus. Nat Rev Endocrinol. 2009;5(5):262-269.

70. Rodbard HW, Jellinger PS, Davidson JA, et al. Statement by an American Association of Clinical Endocrinologists/American College of Endocrinology consensus panel on type 2 diabetes mellitus: an algorithm for glycemic control. Endocr Pract. 2009;15(6):540-559.
Therapeutics and Clinical Risk Management

\section{Publish your work in this journal}

Therapeutics and Clinical Risk Management is an international, peerreviewed journal of clinical therapeutics and risk management, focusing on concise rapid reporting of clinical studies in all therapeutic areas outcomes, safety, and programs for the effective, safe, and sustained use of medicines. This journal is indexed on PubMed Central, CAS,

\section{Dovepress}

EMBase, Scopus and the Elsevier Bibliographic databases. The manuscript management system is completely online and includes a very quick and fair peer-review system, which is all easy to use. Visit http://www.dovepress.com/testimonials.php to read real quotes from published authors. 